\title{
Predicting Factors of Maternal Depression During the First Three Months After Delivery Among Low- Income Family in Indonesia
}

\author{
Irma Nurbaeti \\ Nursing Program, Faculty of Medicine and Health Sciences \\ State Islamic University Syarif Hidayatullah \\ Jakarta, Indonesia \\ irma.nurbaeti@uinjkt.ac.id
}

\author{
Associate Professor Wannee Deoisres \\ Faculty of Nursing, Burapha University \\ Chon Buri, Thailand
}

\begin{abstract}
Maternal depression is recognized as a significant mental health problem in postpartum circumstances, particularly, prevalence may be considerably higher among low-income. The purpose of study was to identify average maternal postpartum depression and its predicting factors among low-income family during the first three months after delivery in Indonesia mothers. A cross sectional study was carried out, of 206 mothers in the first three months postpartum with family income monthly less than 3000000 IDR (US\$230) who visited maternal and child health clinic in both Public Health Center, South Tangerang District, Banten Province and South Jakarta District, Jakarta Province, Indonesia. The participants were recruited by purposive sampling. Data collection was conducted during December 2015 to May 2016 by visiting home. Structured questionnaires for data collection included general information, Edinburgh Postnatal Depression Scale (EPDS), the Dyad Adjustment Scale (DAS), the Life Events Questionnaire (LEQ), Childcare Stress Inventory (CSI), and the Postpartum Support Questionnaire (PSQ). Descriptive statistics and standard multiple regression were employed for data analysis. Sixty-nine $(33.5 \%)$ mothers experienced postpartum depression. Childcare stress, marital satisfaction and stressful life events could explain $51.1 \%$ of the variance in postpartum depression among low-income family $\left(R^{2}=0.511, F\right.$ $=41.766, p$-value $<0.001)$. Significant predictors were childcare stress $(\boldsymbol{\beta}=0.408, P$-value $<0.001)$, followed by stressful life events $(B=0.310, p$-value $<0.001)$, and marital satisfaction $(B=$ $\mathbf{- 0 . 1 5 5}, p$-value $<0.05$ ). Low income family mothers with higher childcare stress, less satisfied with the marital relationship, and perceived the higher level of stressful life events may be important targets for maternal postpartum depression prevention in postpartum period.
\end{abstract}

Keywords-Indonesia; Low income family; Nursing; Postpartum depression

\section{INTRODUCTION}

Maternal depression is the most common complication of childbearing, affecting women and their families [1]. Maternal depression can begin as early as 4 weeks postpartum [2]. The average of maternal depression was more than $10 \%$ over the world. In Indonesia estimates reported to range from $2.5 \%-22.3 \%[3,4]$. The prevalence may be considerably higher among low-income and ethnic minority women $[5,6]$. Despite evidence of higher risk, most low-income women with PPD are not diagnosed or treated [5].

The effect of PPD may occur on the woman herself, her partner, and her young child, especially her parenting behavior maternal-infant relationship. This effect happens over years in their life. Interactions between depressed mothers and their infants supports showed less affectionate behavior, responded less to infant cues and withdraw, or had hostile/ intrusive interactions with their infants $[7,8]$.

Multiple factors have played a role in the development of PPD. Predictors of maternal depression related to family factors, including social support, life event, marital relationship, and child care stress [1, 9-13]. However, study of maternal depression among low income family has limited in Indonesia. The purpose of this study is to identify average of maternal depression and its predicting factors among lowincome family during the first three months after delivery in Indonesia.

\section{METHODS}

\section{A. Design and study settings}

A crossectional design, conducted during December 2015 to February 2016 at maternal and child health clinic Public Health Center, South Tangerang District, Banten Province and South Jakarta District, Jakarta Province, Indonesia. Jakarta Province is the capital of the Republic of Indonesia as an urban area, while Banten Province which representative a rural area.

B. Sample

An eligible participants consisted of 206 low-income families, who had lived with husband, the baby born weight $\geq 2500$ gram, healthy, and mature, and be able to read, write and speak Bahasa Indonesia. However, subjects who are mentally ill or have a family history of psychiatric problems and baby stillbirth will be excluded. Samples were recruited by consecutive sampling technique. 


\section{Instruments}

The instrumentation used in this study included Edinburgh Postnatal Depression Scale (EPDS), the Dyad Adjustment Scale (DAS), the Life Events Questionnaire (LEQ), Childcare Stress Inventory (CSI), and the Postpartum Support Questionnaire (PSQ).

\section{Edinburgh Postnatal Depression (EPDS) Scale}

Edinburgh Postnatal Depression Scale Indonesia version was used to measure maternal depression. Originally EPDS has been developed by Cox (1987), is a self-report questionnaire, specially designed to detect postnatal depression [14]. It consists of 10 items, such as being able to laugh and enjoy, being anxious or scared or worried, selfblaming, inability to cope, depressive thoughts, sleeping difficulties based on depression, and suicidal thoughts. The scale rates the intensity of depressive symptoms presents during the previous seven days. Each item is scored on a 4point scale ( 0 to 3 ). The total score is $0-30$. A cut-off point of $13(\geq 13)$ points is used to detect depressive mothers [15].

\section{Dyad Adjustment Scale (DAS)}

The Dyad Adjustment Scale (DAS) contains 32-questions and was developed by Spanier [16] to measure marriage satisfaction. The four DAS subscales consist of Dyadic consensus (13 five-point Likert-type items), Dyadic Satisfaction (10 five-point Likert-type items), Dyadic Cohesion (5 five-point Likert-type items) and Affective expression (4 five-point Likert-type items). The possible scores ranged from 0 to 150 points.

\section{Life Events Questionnaire (LEQ)}

A number of stressful life events during pregnancy and postpartum periods are measured by the life events questionnaire. The principal investigator will modify the instrument within Indonesia's context according to the life stress items in the postpartum depression predictors inventory-revised [17] and the life events questionnairerevised [18]. The life events questionnaire contains three subcategories: family, work, and finance. For each of the items, the respondents indicate whether or not they have experienced certain events.

\section{Childcare Stress Inventory (CSI)}

The Childcare Stress Inventory (CSI) was developed by Cutrona (1983) and designed to index stressful to take care of the baby in the first month of parenthood, including health and feeding problems with the baby [19].

\section{Postpartum Support Questionnaire (PSQ)}

The Postpartum Support Questionnaire (PSQ) developed by Logsdon was to measure postpartum support [20]. The PSQ can be used anytime during the postpartum period and contains 34 items for expected and received emotional, material, informational and comparison support. The score for each item is ranked from 0 to 7 . The total possible scores range from 0 to 238 .
However, the DAS, LEQ, CSI, and PSQ have never been used in Indonesian women. While EPDS have been in Indonesia version. Therefore, the researcher conducted back translation with permission from the developer. Then, a convenience sample of 70 women who had 1 month postpartum and more was collected from Maternal and Child Health Clinics Depok, West Java Province, Indonesia. The alpha Cronbach of EPDS, PSQ, CSI, DAS, and LEQ were $0.802,0.925,0.826,0.730$, and 0.780 , respectively.

\section{Data Collection}

After IRB approval from Faculty of Nursing, Burapha University, researcher selected randomly the following sites: Public health center in South Tangerang District (under subdistrict Pamulang, and Ciputat Timur), Banten Province and South Jakarta District (under sub-district Kebayoran lama and Cilandak), trained 4 research assistants in each subdistrict as an enumerator. Trained 2 days (each day around 3 hours) in data collection in which researcher explained the research objectives, the role of research assistants and the instruments that will be used, provided a manual for data collection, and sheet to control each participant of the sample.

Initially, the researcher or research assistants met proposed participants at each clinic in 2 ways, First, when mothers visit one week after birth to control her baby and herself. Thus, invited subjects who met inclusion criteria and did informed consent, and then the researcher or research assistant asked for the phone number of participants and address in detail for visiting her home. Second, we asked patients monthly data from health workers at each delivery room, include name, parity, address, baby status. We visited her home and asked to participate in research if they agreed we did informed consent. Data collection was conducted at her home estimated at the first three months after birth. Researcher or assistant researcher asked the participants to complete the questionnaire within 30-45 minutes.

\section{E. Statistical Analyses}

Data analyses were performed with a statistical software program in response to the research objectives. The descriptive statistics was used to describe the studied variables. The standard multiple regression was performed to determine the predictors of postpartum depression which include childcare stress, postpartum support, marital satisfaction and life event.

\section{RESULT}

Average Postpartum Depression

Assessing maternal postpartum depression among lowincome family in the samples yielded scores on the EPDS from 206 samples, ranged from 0 to 24, with a mean 8.36 $(\mathrm{SD}=5.48)$. Using cut-off scores 13 or greater to differentiate depressed from non-depressed mothers, 69 (33.5\%) mothers experienced depression, and 137 (66.5\%) had no-depressed. 
The mean score of childcare stress, postpartum support, marital satisfaction and life event were $106.62( \pm 125.961)$, $125.81 \quad( \pm 50.908), \quad 120.96 \quad( \pm 12.077), \quad 9.42 \quad( \pm 7.974)$, respectively (Table 1). The correlation among all predictor variables is presented in Table 2. Most of the predictors are weakly to moderately correlated, which indicates sufficient discrimination between the various construct.

TABLE 1. DEPENDENT VARIABLES

\begin{tabular}{|l|c|c|c|}
\hline \multicolumn{1}{|c|}{ Variable } & Min - Max & Mean & SD \\
\hline Childcare stress & $0-650$ & 106.62 & 125.96 \\
\hline Postpartum Support & $20-238$ & 125.81 & 50.91 \\
\hline Marital Satisfaction & $54-146$ & 120.96 & 12.08 \\
\hline Stressful Life Event & $0-36$ & 9.42 & 7.97 \\
\hline
\end{tabular}

\section{Predicting of Maternal Depression}

TABLE 2. CORRELATION, MEANS AND STANDARD DEVIATIONS OF STUDY VARIABLES $(\mathrm{N}=206)$

\begin{tabular}{|l|l|l|l|l|l|}
\hline Variable & $\mathbf{1}$ & $\mathbf{2}$ & $\mathbf{3}$ & $\mathbf{4}$ & $\mathbf{5}$ \\
\hline $\begin{array}{l}\text { 1.Maternal } \\
\text { depression }\end{array}$ & 1 & & & & \\
\hline $\begin{array}{l}\text { 2.Childcare } \\
\text { stress }\end{array}$ & $0.621^{* *}$ & 1 & & & \\
\hline $\begin{array}{l}\text { 3.Postpartum } \\
\text { Support }\end{array}$ & $-0.153^{*}$ & -0.128 & 1 & & \\
\hline $\begin{array}{l}\text { 4.Marital } \\
\text { Satisfaction }\end{array}$ & $-0.428^{* *}$ & $-0.340^{* *}$ & $0.188^{*}$ & 1 & \\
\hline $\begin{array}{l}\text { 5.Stressfull } \\
\text { Life Event }\end{array}$ & $0.563^{* *}$ & $0.455^{* *}$ & -0.050 & $-0.386^{* *}$ & 1 \\
\hline $\begin{array}{l}\text { Mean } \\
\text { SD }\end{array}$ & 8.36 & 106.62 & 125.81 & 120.96 & 9.42 \\
& 5.480 & 125.961 & 50.908 & 12.077 & 7.974 \\
\hline
\end{tabular}

Table 2 showed the correlations, means, and standard deviations among the study variables. Table 3 presented a result from standard multiple regression analysis which indicated that childcare stress, marital satisfaction and life event could explain $51.1 \%$ of the variance in maternal depression among low income family in Indonesia $\left(R^{2}=0.511, F=41.766, P\right.$-value $\left.<0.001\right)$. Particularly, childcare stress explained the most variance in maternal depression among low income family $(\beta=0.408, \quad p$-value $<0.001)$, followed by life event $(\beta=0.310, p$-value $<0.001)$, and marital satisfaction $(\beta=-0.155, p$-value $<0.05)$.

TABLE 3 PREDICTORS OF MATERNAL DEPRESSION (N=206)

\begin{tabular}{|c|c|c|c|c|}
\hline Variable & $\mathbf{B}$ & SE & Beta & $\mathbf{T}$ \\
\hline $\begin{array}{l}\text { Constant Childcare } \\
\text { stress }\end{array}$ & $\begin{array}{l}13.64 \\
0.018\end{array}$ & $\begin{array}{l}3.19 \\
0.003\end{array}$ & 0.408 & $\begin{array}{l}4.30 * * * \\
6.542 * * *\end{array}$ \\
\hline Postpartum Support & -0.006 & 0.005 & -0.055 & -1.081 \\
\hline Marital Satisfaction & -0.070 & 0.025 & -0.155 & $-2.794 *$ \\
\hline Life Event & 0.213 & 0.040 & 0.310 & $5.359 * * *$ \\
\hline
\end{tabular}

Mothers among low income family who experienced stress to taking care of children, less satisfied with marital relationship, and perceived higher level of stress on life event were more likely have maternal depression at the first three months postpartum.

\section{DISCUSSION}

The findings showed that at the first three month postpartum, prevalence of PPD was higher (33.5\%) than prevalence od PPD in general population of postpartum mothers in Indonesia.was $2.25 \%^{4}$ to $22.3 \%{ }^{3}$

Analyses showed that childcare stress, life stress, and marital satisfaction predicted PPD in low income family. These findings supported Beck's theory that some predictors had associated with PPD [21].

Mothers with a higher level of childcare stress exhibited high the EPDS scores. Childcare stress represents a relatively under research risk factor for the development of PPD. This finding was consistent with previous study. Infant-sleep problems had association with childcare stress and increasing PPD over three months in the postpartum period [22]. A higher childcare stress scores related to infant sleep disturbance and more frequent feeding were associated with PPD, especially if those matter continued as long as four month after birth [23]. This demonstrates that childcare stress should have an important place in research aimed at contributing PPD. Planning intervention to promote appropriate program in order to reduce childcare stress in postpartum period is necessary.

The present study found that mothers with a higher level of life stress showed high the EPDS scores. A number of life stress during pregnancy and labor may lead to PPD. Mental and physical problem during the previous one year before labor were associated with PPD among $18 \%$ of the mothers who experienced the first PPD and $82 \%$ recurrent PPD while negative life stress associated only with recurrent PPD [24]. Infant-related problems including premature infant, infants with illnesses or disabilities, or infant with temperamentally difficult might be very stressful experiences for the mother and at risk for developing PPD [25].

Marital dissatisfaction emerged as one of significant predictor of maternal depression. This study was consistent with prior study [26, 27]. Previous study showed that mothers had existed depression having low marital satisfaction compared to the non-depressed mothers during the postpartum period [26]. Similarly, mothers who had less marital satisfaction increased the probability of PPD during the first one year postpartum [27].

Interestingly, this present study found that scores of social supports were not significant as predictor of maternal depression. This result did not support Beck's theory [21] and was not consistent with prior studies [26, 27] that need for support and perceived available support emerged as important predictors of PPD in the first six months after birth [28]. This is in accordance with previous study that several dimensions of perceived social support were predictive of the level of PPD. The researcher believes that there is prior strong evidence that increased social support is associated with decreased risk of PPD. The present finding suggested 
that an increasing social support in postpartum care may comprise a contributing factor in the reduction prevalence of PPD.

\section{CONCLUSION}

In conclusion, the findings in this study highligh the predictor of maternal depression postpartum period including child care stress, marital satisfaction, and life stress.

\section{ACKNOWLEDGMENT}

We would like to thank to the Ministry of Religious Affairs, The Republic of Indonesia on finding supported, and all the mothers who participated in this study.

\section{REFERENCES}

[1] O'Hara MV,McCabe JE.Postpartum depression: Current status and future direction. Annu Rev Clin Psycho.2013; 9: 379-407

[2] American Psychiatric Association. Diagnostic and statistical manual of mental disorders (5th ed., text revision). Washington, DC;2013.

[3] Andajani-Sutjahjo, MandersonL, Astbury J. Complex emotions, complex problems: Understanding the experiences of perinata depression among new mothers in urban Indonesia. Cult Med Psychiatry. 2007; 31(1): 101-122.

[4] Idaiani S, Basuki B. Postpartum depression in Indonesian women: A national study. Health Science J Indonesia. 2012; 3(1): 3-8

[5] Center for Disease Control and Prevention (2009). Maternal and infant health. September 1, 2009. http://www.cdc.gov/reproductivehealth/MaternalInfantHealth/. Accessed 1 October 2017.

[6] Gavin NI, Gaynes BN, Lohr KN, et al. Perinatal depression: a systematic review of prevalence and incidence. Obstetrics and Gynecology. 2005, 106, 1071-1083

[7] Field T. Postpartum depression effects on early interactions, parenting, and safety practices: A review. Infant Behavior and Development. 2010, 33(1), 1-6

[8] Goodman JH. Influences of maternal postpartum depression on fathers and on father- infant interaction. Infant Mental Health Journal. 2008, 29 (6). 624-643

[9] Clout D, Brown R. Sociodemographic, pregnancy, obstetric, and postnatal predictors of postpartum stress, anxiety and depression in new mothers. Journal of Affective Disorders. 2015, 188, 60-67

[10] Hegde S. Latha KS, Bhat SM, Sharma PSVN, et al. Postpartum Depression: Prevalence and Associated Factors among Women in India. J Womens Health, Issues Care. 2012, 1,1, 1-7. doi:10.4172/2325-9795.1000101

[11] Paulson, J.F., Dauber S., Leiferman J.A., (2011). Individual and Combined Effects of Postpartum Depression in mothers and fathers on parenting behavior, http://pediatrics.aappublications.org/content/118/2/659.full.htm

[12] Roomruangwong C, Epperson CN. Perinatal depression in Asian women: prevalence, associated factors, and cultural aspects. Asian Biomedicine. 2011 5(2), 179 - 193

[13] De Sylve'n SM, Thomopoulos TP, Kollia N, Jonsson M, et al. Correlates of postpartum depression in first time mothers without previous psychiatric contact European Psychiatry. 2017, 40, 4-12

[14] Cox JL, Holden JM, Sagovsky R. Detection of postnatal depression. Development of the 10-item Edinburgh postnatal depression scale. Br J Psychiatry. 1987; 150, 782-786.

[15] Bell AF, Carter CS, Davis JM,et al. Childbirth and symptoms of postpartum depression and anxiety: a prospective birth cohort study. Arch Women's Mental Health. 2016;19:219-227 DOI 10.1007/s00737-015-0555-7

[16] Spanier GB. Measuring dyadic adjustment: new scales for assessing the quality of marriage and similar dyads. J Marriage and the Family. 1976; 38: 15-28

[17] Beck CT, Records K. Rice M. Further Development of the Postpartum Depression Predictors Inventory Revised. J Obstetric, Gynecologic, \& Neonatal Nurs. 2006, 35, 735-745.

[18] Norbeck JS. Modification of life event questionnaires for use with female respondents. Res Nurs Health. 1984; 7(1):67-71

[19] Cutrona CE. Causal attributions and perinatal depression. J Abnormal Psychology.1983; 92(2): 161-172

[20] Logsdon MC, Usui W, Birkimer JC,et al. The Postpartum Support Questionnaire: Reliability and validity. J Nurs Meas.1996; 4(2): 129142 .

[21] Beck CT. Predictors of postpartum depression: An update. Nurs Res. 2001; 50: 275-285.

[22] KettunenP, Koistinen E, Hintikka J. The connections of pregnantdelivery-, and infant-related risk factors and negative life events on postpartum depression and their role in first and recurrent depression. Hindawi Publishing Corporation Depression Research and Treatment. Article 2016. ID 2514317,7 pages. http://dx.doi.org/10.1155/2016/2514317

[23] Werner E, Miller M, Osborne LM, et al. Preventing postpartum depression: review and recommendations. Arch Women's Mental Health. 2015; 18:41-60.

[24] Hegde S, Latha KS, Bhat SM, et al. A. Postpartum depression: Prevalence and associated factors among women in India. J Women's Health Care Issues.2012; 1(1): 1-7. doi:10.4172/23259795.1000101

[25] Dennis CL, Ross L. Relationships among infant sleep patterns, maternal fatigue, and development of depressive symptomatology. Birth. 2005; 32:187-193. doi:10.1111/j.0730-7659.2005.00368.x

[26] Boratav HB, Toker O, Kuey L. Postpartum depression and its psychosocial correlates: A longitudinal study among a group of women in Turkey.Women Health. 2016;56(5): 502-521

[27] Klainin P, Arthur DG. Postpartum depression in Asian cultures: A literature review. Int J Nurs Stud. 2009; 46, 1355-1373

[28] Haga SM, Ulleberg P, Slinning K, et al. A longitudinal study of postpartum depressive symptoms: Multilevel growth curve analyses of emotion regulation strategies, breastfeeding self-efficacy, and social support. Arch. Women's Mental Health. 2012; 15: 175-184 